
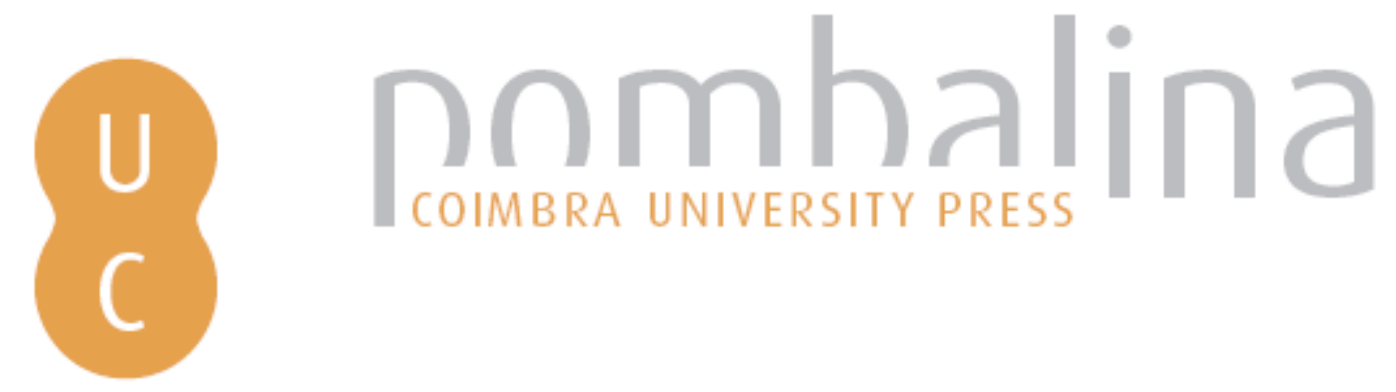

\title{
Análise da cobertura vegetal, espaços livres e áreas verdes da área urbana de Ponta Grossa - PR utilizando imagem de satélite de alta resolução
}

Autor(es): $\quad$ Queiroz, Dulcina; Carvalho, Silvia Méri

Publicado por: Imprensa da Universidade de Coimbra

URL

persistente: URI:http://hdl.handle.net/10316.2/37080

DOI: $\quad$ DOI:http://dx.doi.org/10.14195/978-989-26-0983-6_27

Accessed : $\quad$ 26-Apr-2023 10:50:04

A navegação consulta e descarregamento dos títulos inseridos nas Bibliotecas Digitais UC Digitalis, UC Pombalina e UC Impactum, pressupõem a aceitação plena e sem reservas dos Termos e Condições de Uso destas Bibliotecas Digitais, disponíveis em https://digitalis.uc.pt/pt-pt/termos.

Conforme exposto nos referidos Termos e Condições de Uso, o descarregamento de títulos de acesso restrito requer uma licença válida de autorização devendo o utilizador aceder ao(s) documento(s) a partir de um endereço de IP da instituição detentora da supramencionada licença.

Ao utilizador é apenas permitido o descarregamento para uso pessoal, pelo que o emprego do(s) título(s) descarregado(s) para outro fim, designadamente comercial, carece de autorização do respetivo autor ou editor da obra.

Na medida em que todas as obras da UC Digitalis se encontram protegidas pelo Código do Direito de Autor e Direitos Conexos e demais legislação aplicável, toda a cópia, parcial ou total, deste documento, nos casos em que é legalmente admitida, deverá conter ou fazer-se acompanhar por este aviso. 


\section{$\forall$ \\ TAS DAS I JORNADAS LUSÓFONAS DE CIÊNCIAS E TECNOLOGIAS DE INFORMAÇÃO GEOGRÁFICA}

Editores

José Gomes dos Santos

Cidália Fonte

Rui Ferreira de Figueiredo

Alberto Cardoso

Gil Gonçalves

José Paulo Almeida

Sara Baptista 


\title{
ARTIGO 27
}

\section{ANÁlISE DA COBERTURA VEGETAL, ESPAÇOS LIVRES E ÁreAs VERDES DA ÁREA URBANA DE PONTA GROSSA- PR UTILIZANDO IMAGEM DE SATÉLITE DE ALTA RESOLUÇÃo}

\author{
QUEIROZ, Dulcina ${ }^{1}$ \& CARVALHO, Silvia Méri ${ }^{2}$
}

\footnotetext{
${ }^{1}$ Doutoradanda do programa de pós- graduação em Gestão do território da Universidade Estadual de Ponta Grossa. (Brasil) Laboratório de Estudos Socioambientais-LAESA (Avenida Carlos Cavalcanti, 4748, CIPP -sala 114, Campus Uvaranas, Ponta Grossa-PR, Brasil. CEP:84030-900) email: dulcinah@gmail.com 2 Docente Doutora do programa de Pós-Graduação em Geografia da Universidade Estadual de Ponta Grossa(Brasil) email: silviameri@brturbo.com.br
}

\section{RESUMO}

Foi analisada a distribuição da cobertura vegetal, espaços livres e áreas verdes para o ano de 2004 na área urbana de Ponta Grossa. Foram realizadas quantificações dos espaços livres e áreas verdes por bairro, a partir de produtos gerados pelas geotecnologias. Verificou-se que a cobertura vegetal ocupava $49 \%$ do total da área urbana. Os espaços livres ocupavam 2,5\% de área composto por 230 espaços dos quais: 132 campos de esportes, 63 praças, 4 parques, 6 cemitérios e 8 clubes de lazer. As áreas verdes ocupavam 2\% distribuídos em 102 espaços. Embora os resultados numéricos para cada categoria sejam indicadores positivos, a distribuição compromete a sua eficácia.

\section{PALAVRAS-CHAVE}

Geotecnologias, Mapeamento, Área urbana. 
LAND COVER ANAlysis in ponta grossa (PR, Brazil) USING HIGH RESOLUTION SATELLITE IMAGERY

\begin{abstract}
The thesis classifies Ponta Grossa's vegetation, open spaces and green areas. Analysis its distribution along 2004. In this context, it quantifies open spaces and green areas per borough by means of geotechnologies. In turn, vegetal coverage had $49 \%$. Finally, open space had an area of 2,5\% composed by 230 spaces, they are: 132 sport fields, 63 public squares, 4 parks, 6 cemeteries and 8 clubs.. In summary, in spite of the fact the numeric results for each category can be classified as satisfactory, their distribution can not and might impairing their effectiveness.
\end{abstract}

\title{
KEYWORDS
}

Geotechnology, Mapping, Urban area.

\section{INTRODUÇÃo}

O processo de urbanização tem se intensificado nos últimos anos principalmente nos países em vias de desenvolvimento, (ALMEIDA, 1999), onde se enquadra grande parte dos países da America Latina, incluindo o Brasil.

Dentro deste contexto a maioria das cidades brasileiras, incluindo Ponta Grossa tem passado por um período de intensa urbanização (SAHR, 2001) que levou à diminuição do verde urbano e redução dos aspectos relacionados com o meio natural e por isso, pretende-se analisar a distribuição espacial da cobertura vegetal, espaços livres e áreas verdes na área urbana de Ponta Grossa- Paraná recorrendo a uma imagem de satélite de alta resolução.

\section{METODOLOGIA}

\subsection{Recorte Espacial}

O recorte espacial incide sobre o espaço urbano da cidade de Ponta Grossa, localizada nas coordenadas $25^{\circ} 09^{\prime} \mathrm{S}$ e $50^{\circ} 16^{\prime} \mathrm{W}$, no $2^{\circ}$ Planalto Paranaense da região dos Campos Gerais, estado do Paraná, região Sul 
do Brasil. A área urbana é composta por 16 bairros que ocupavam 172,41 $\mathrm{km}^{2}$ conforme a Lei $\mathrm{n}^{\circ} 5949$ de 16 de Abril de 1998.

\subsection{Procedimentos}

1 Etapa - Levantamento bibliográfico: Considerou-se então segundo a metodologia que foi adaptada por Buccheri Filho e Nucci (2006) baseado em Cavalheiro et al, (1999).

2 Etapa - Elaboração dos mapas para cada variável sobre uma base de dados com enfoque na área urbana de Ponta Grossa. Foi utilizada imagem-mosaico IKONOS do ano de 2004 ortorretificada com resolução de 1 metro, já georreferenciado e ortorretificado no sistema de coordenadas UTM (metros) e Datum Horizontal South American 1969-SAD69. O mapeamento foi elaborado em escala de detalhe (1:5.000) por meio de vetorização em tela da Imagem de satélite já fusionada e corrigida, composta pelas bandas da faixa do visível que permitiram a composição colorida R3.G2. B1- verdadeira-cor.

3 Etapa - Por último procedeu-se a análise integradora dos resultados obtidos e considerações.

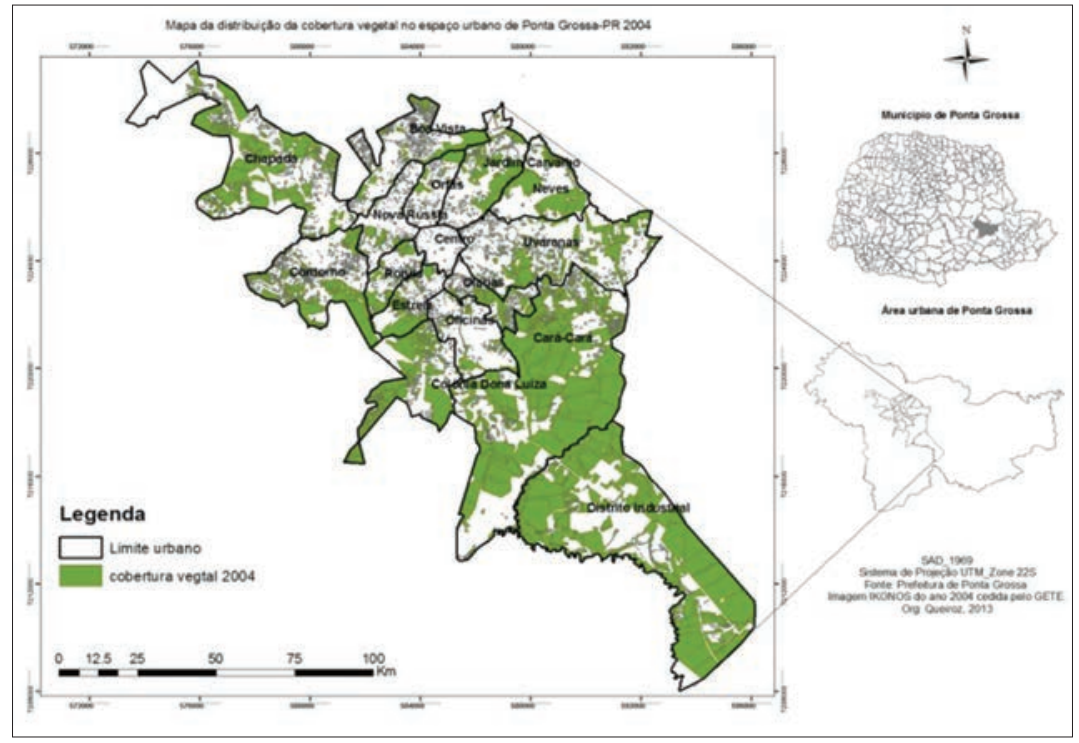

Figura 1 - Mapa da distribuição da cobertura vegetal na área urbana de Ponta Grossa 


\subsection{Distribuição dos espaços livres}

Delimitou-se 230 espaços livres de acordo com o conceito aplicado, distribuídos pelos 16 bairros. Estes espaços ocupam um total de $4,4 \mathrm{~km}^{2}$ $\left(4376.114 \mathrm{~m}^{2}\right)$ da área urbana, ou seja, 2,5\%. Compõem esses espaços, 132 quadras esportivas, 63 praças, 4 parques, 6 cemitérios e 8 clubes de lazer.

Dos 230 espaços livres 96 correspondem a espaços livres públicos, 42 correspondem a potencialmente coletivos e 92 a espaços livres privados. Dos 4,4 km² ocupados pelos espaços livres espaços livres públicos correspondem a $1,27 \mathrm{~km}^{2}$, os espaços livres potencialmente coletivos 0,569 $\mathrm{km}^{2}$, e os privados $2,36 \mathrm{~km}^{2}$ da área total.

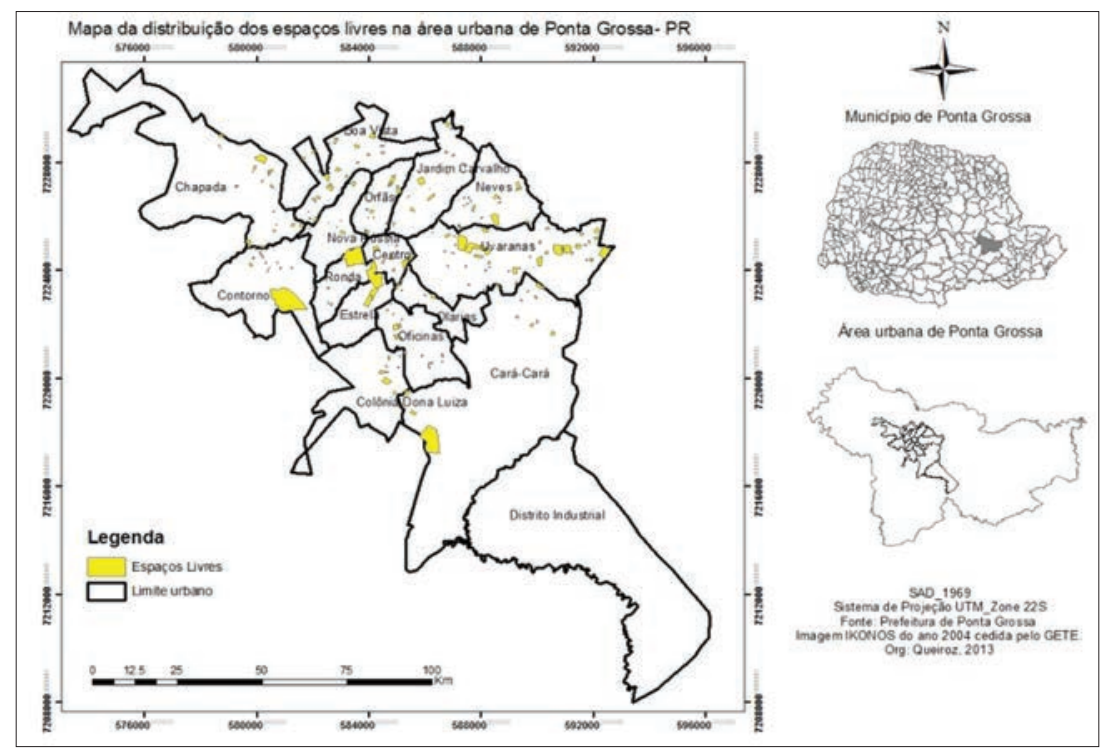

Figura 2 - Mapa da distribuição dos espaços livres na área urbana de Ponta Grossa

\subsection{Distribuição das áreas verdes}

Dos 230 espaços livres, 102 deles são consideradas áreas verdes. Dos 4.376,114 $\mathrm{m}^{2}$ ocupados pelos espaços livres $3.468,012 \mathrm{~m}^{2}\left(3,5 \mathrm{~km}^{2}\right)$ são áreas verdes o que corresponde a $2 \%$ da área urbana total. As áreas verdes públicas ocupam 1,7 km² distribuídos em 42 espaços. As 17 áreas verdes potencialmente coletivas ocupam $0,7 \mathrm{~km}^{2}$; e as áreas verdes privadas correspondem $1 \mathrm{~km}^{2}$. 


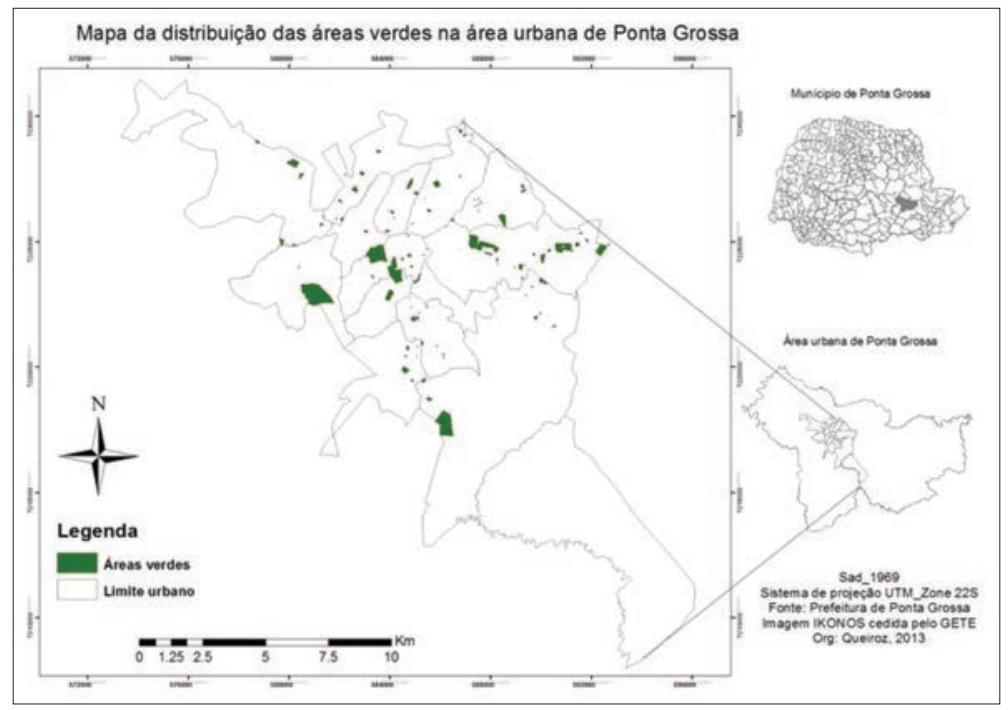

Figura 3 - Mapa da distribuição das áreas verdes na área urbana de Ponta Grossa

\section{CONCLUSÕeS}

O recurso à imagem de satélite de alta resolução, permitiu mediante a configuração espacial de cada variável:

- Analisar visualmente de forma rápida e mais conclusiva a distribuição no espaço urbano das variáveis em análise e calcular com precisão a área que cada variável em análise ocupa no espaço urbano.

- Concluir que apesar dos valores parecerem positivos quanto ao seu número, a distribuição dos espaços livres e áreas verdes aparece fragmentada e concentrada nos bairros mais centrais, dificultando as populações periféricas de usufruírem desses espaços.

- Inferir que o processo de urbanização e de expansão urbana não contemplou eficazmente a criação de novas áreas verdes.

- Apenas 3,5 dos 50,4\% de cobertura vegetal são sob a forma de áreas verdes.

\section{BIBLIOGRAFIA}

AlmeidA, J R; Marques, Telma; Moraes, Frederico; Bernado, José (1999). Planejamento ambiental. 2a edição, Thex Editora, Rio de Janeiro. 
BUCCHERI FILHO, Alexandre. Theobaldo (2006); NUCCI, João Carlos. (2006). Espaços livres, áreas verdes e cobertura vegetal no Bairro Alto da XV Curitiba/PR, n. 18. Rev. Departamento de Geografia. 2006. p. 48-59.

SAHR, Cecilia (2001) Estrutura interna e dinâmica social na cidade de Ponta Grossa. In: DITZEL, C. de H. M.; SAHR, C. L. L. Espaço e Cultura: Ponta Grossa e os Campos Gerais. Ponta Grossa: Editora UEPG, 2001. P. 13- 36. 
Série Documentos

Imprensa da Universidade de Coimbra

Coimbra University Press

2015

- U M

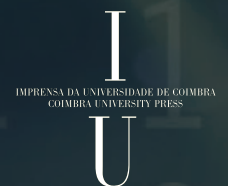

